\title{
STEM learning through engineering design: fourth-grade students' investigations in aerospace
}

\author{
Lyn D English* and Donna T King
}

\begin{abstract}
Background: Internationally, there is a growing concern for developing STEM education to prepare students for a scientifically and technologically advanced society. Despite educational bodies lobbying for an increased focus on STEM, there is limited research on how engineering might be incorporated especially in the elementary school curriculum. A framework of five comprehensive core engineering design processes (problem scoping, idea generation, design and construction, design evaluation, redesign), adapted from the literature on design thinking in young children, served as a basis for the study. We report on a qualitative study of fourth-grade students' developments in working an aerospace problem, which took place during the first year of a 3-year longitudinal study. Students applied design processes together with their mathematics and science knowledge to the design and redesign of a 3-D model plane.

Results: The study shows that through an aerospace engineering problem, students could complete initial designs and redesigns of a model plane at varying levels of sophistication. Three levels of increasing sophistication in students' sketches were identified in their designs and redesigns. The second level was the most prevalent involving drawings or templates of planes together with an indication of how to fold the materials as well as measurements linked to the plane's construction. The third level incorporated written instructions and calculations. Students' engagement with each of the framework's design processes revealed problem scoping components in their initial designs and redesigns. Furthermore, students' recommendations for improving their launching techniques revealed an ability to apply their mathematics knowledge in conjunction with their science learning on the forces of flight. Students' addition of context was evident together with an awareness of constraints and a consideration of what was feasible in their design creation. Interestingly, students' application of disciplinary knowledge occurred more frequently in the last two phases of the engineering framework (i.e., design evaluation and redesign), highlighting the need for students to reach these final phases to enable the science and mathematics ideas to emerge.

Conclusions: The study supports research indicating young learners' potential for early engineering. Students can engage in design and redesign processes, applying their STEM disciplinary knowledge in doing so. An appropriate balance is needed between teacher input of new concepts and students' application of this learning in ways they choose. For example, scaffolding by the teacher about how to improve designs for increased detail could be included in subsequent experiences. Such input could enhance students' application of STEM disciplinary knowledge in the redesign process. We offer our framework of design processes for younger learners as one way to approach early engineering education with respect to both the creation of rich problem experiences and the analysis of their learning.
\end{abstract}

Keywords: STEM learning; Design processes; Engineering; Aerospace; Problem solving; Elementary school

\footnotetext{
* Correspondence: I.english@qut.edu.au

Faculty of Education, Queensland University of Technology, Victoria Park

Road, Kelvin Grove, 4059 Brisbane, Queensland, Australia
}

\section{空 Springer}

(C) 2015 English and King. Open Access This article is distributed under the terms of the Creative Commons Attribution 4.0 International License (http://creativecommons.org/licenses/by/4.0/), which permits unrestricted use, distribution, and reproduction in any medium, provided you give appropriate credit to the original author(s) and the source, provide a link to the Creative Commons license, and indicate if changes were made. 


\section{Background}

STEM education at the pre-college levels is gaining increased international interest, with such learning considered an integral component of a progressive twenty-first century curriculum (Honey et al. 2014; Katehi et al. 2009; National Research Council 2014). Educating a more scientifically literate community is one of the core goals of STEM education (Shaughnessy 2013), yet this goal takes a long time to develop and needs to begin with the earliest grades if societies are to nurture the scientists and engineers of the future (National Research Council 2009).

Although educational bodies in many nations have lobbied in support of an increased focus on STEM education in schools (e.g., Honey et al. 2014; National Research Council 2014), the nature of such learning experiences and how these might be integrated within the curriculum remain open to debate. With the emergence of new journal and book publications devoted to STEM education (e.g., National Research Council 2014; Purzer et al. 2014) the field is broadening to include various interpretations of such education and the opportunities it can offer for school students.

One aspect that remains in need of greater attention is the inclusion of engineering experiences in STEM curricula, especially at the elementary level, even though the contributions of engineering have been well documented. It has been noted, for example, how such experiences can develop young students' appreciation and understanding of the various roles of engineering in shaping societies and how it can contextualize mathematics and science principles to enhance achievement, motivation, and problem solving (Cunningham and Lachapelle 2014; Diaz and King 2007; English 2015; Holmes et al. 2007; Moore et al. 2014a; Stohlmann et al. 2012; Zawojewski et al. 2008). What is perhaps not emphasized sufficiently in the literature is how engineering can also link students' learning across other disciplines such as literacy, history, and geography (Hudson et al. 2014; Miaoulis 2014).

With global recognition of the importance of STEM education, concerns have arisen from both research and curriculum perspectives about the lack of a unified focus and the need for greater integration of the four disciplines (e.g., Atkinson and Mayo 2010; Barrett et al. 2014; Berland 2014; National Research Council 2014; STEM Taskforce Report, 2014). In the United States, for example, both the Common Core State Standards for Mathematics (http://www.corestandards.org/Math/) and the Next Generation Science Standards (NGSS; http:// www.nextgenscience.org/) are advocating for more interdisciplinary approaches to STEM education. The NGSS specifically includes core practices and concepts from engineering alongside those for science, highlighting the interrelated nature of science and engineering education.
At the same time, concerns have emerged regarding the equitable representation of the four disciplines in integrated approaches (e.g., English 2015; Moore et al. 2014). In particular, mathematics as well as engineering appears in need of increased recognition. As Honey et al. (2014) pointed out, the potential for STEM integration in advancing mathematics learning is less apparent than for science; even engineering-based problems tend to be oriented largely towards the science strand at the expense of mathematics (Honey et al. 2014; Walkington et al. 2014).

The challenge then is how to achieve a more balanced content representation in STEM education. International research is presently limited on how we might effectively attain this goal and promote more connected learning especially in the elementary grades. One promising approach is through engineering design, which is being viewed in a broader and more inclusive light in the NGSS although the emphasis is naturally on its contribution to science education (National Academies Press 2013).

We focus on engineering design as a core link in the problem addressed in this article, namely, the Aerospace Engineering Challenge, as described in the "Methods" section. The problem was conducted during the first year of a longitudinal study on developmental engineering education across grades 4-6. Drawing upon students' learning in their mathematics, science, and technology curricula, our research program developed problems involving the design of 3-D models that are constructed, tested, redesigned, and further tested in generating final products that meet given criteria and constraints.

The present problem was housed within an aerodynamics engineering context, with such a context affording numerous opportunities for interdisciplinary learning (Wright 2006). The mathematics content focused on measurement (including linear, time, speed) and geometry (location, direction, shape, and transformation of shapes), while the science component addressed forces and how they act on objects. Generating design ideas that match constraints and communicating design through a 3-D model addressed the technology content and also contributed to the engineering component. Of particular interest was the students' learning and application of engineering design processes, together with disciplinary knowledge, as they designed, tested, and redesigned a model of a paper airplane that would be airborne for as long as possible. To this end, we investigated the following research questions:

1. What was the nature of students' initial designs and design processes?

2. What were the students' recommendations for improving their approaches to launching their planes? 
3. How did students propose to improve their designs to optimize goal attainment?

4. What learning did students display across the problem?

In setting the scene for our study, we first give consideration to STEM integration in the school curriculum and then address processes of engineering design. The latter formed the basis of the theoretical framework we applied in our longitudinal study.

\section{STEM integration in the school curriculum}

STEM integration is receiving greater attention from multiple perspectives including as a means of addressing national and international student achievement data, as well as preparing students to be competitive in the everchanging global economy (Moore et al. 2014b). Achieving an integrated approach, however, is a complex endeavor, as the Californian Department of Education indicates in citing the axiom, "the whole is more than the sum of the parts" (http://www.cde.ca.gov/PD/ca/sc/ stemintrod.asp ).

The STEM Taskforce Report (2014) illustrates this point further, adopting the strong view that STEM education is far more than a "convenient integration" of its four disciplines, rather, it encompasses "real-world, problem-based learning" that integrates the disciplines "through cohesive and active teaching and learning approaches" (p. 9). The report argues that the disciplines "cannot and should not be taught in isolation, just as they do not exist in isolation in the real world or the workforce" (p. 9). The benefits to be gained from such integration have been variously documented, together with the challenges faced. Studies have indicated that students become better problem solvers, display more positive and motivated learning, and improve in their mathematics and science achievements (e.g., Furner and Kumar 2007a; Stinson et al. 2009). Specifically, through the integration of engineering, students should become more aware of its role and presence in society and be able to apply engineering design processes to the solution of real-world problems (e.g., National Academy of Engineering and National Research Council NAE and NRC 2009a).

Despite the noted benefits of STEM integration, the research is in its infancy and raises many issues in need of attention, especially for the younger grades. One of the challenges facing researchers is how to overcome obstacles to effective STEM integration including the lack of a unified and explicit understanding of what this entails, together with inadequate knowledge of multidisciplinary content many teachers experience (Moore et al. 2014a; Stinson et al. 2009). It is beyond the scope of this study to investigate STEM integration more broadly; rather, the present study represents just one approach to such integration through introducing young students to meaningful engineering-based problems that draw upon their curriculum in mathematics, science, and technology and engage them in the processes of engineering design. Our approach reflects Moore et al.'s (2014a) argument that "Engineering can provide a real-world context for STEM learning if and only if a STEM integration approach is taken" (p. 39). In the next section, we address the processes of engineering design.

\section{Engineering design}

Engineering design has received substantial attention in the literature with a focus on the multifaceted ways in which it can advance students' abilities and dispositions to solve complex, real-world problems (e.g., English, Hudson, \& Dawes, 2013; Cunningham and Hester, 2007; Diefes-Dux et al. 2008; Mehalik et al. 2008; Moore et al. 2014; Purzer et al. 2015). Through engineering design, learners can appreciate that there are multiple ideas and approaches to solving complex problems with more than one solution possible, that numerous tools and representations can be used variously to produce a desired endproduct, and that it is acceptable for initial designs to "fail" (International Technology Education Association (ITEA) 2000; Lachapelle and Cunningham 2014).

More recently, the importance of engineering design to society in general is being emphasized, with Miaoulis (2014) pointing out that design processes are responsible for most of the things that support students' day-to-day lives. This heightened focus on engineering design is evident in the Framework of the National Research Council (2012) where it is considered necessary for a literate society who can effectively tackle issues of local, national, and global importance. Elevating engineering design to the level of scientific inquiry for all grades, the NGSS identifies three core components (National Research Council 2012), reflecting the iterative processes typically cited in the literature: (a) "Defining and delimiting engineering problems" by clearly stating the problem to be solved in terms of criteria for success and given constraints or limits (p. 71); (b) Designing solutions by initially generating possible solutions, then evaluating the promising ones to determine which best meet the problem criteria and constraints; and (c) Optimizing the solution by systematically testing and refining solutions, and improving the final design by trading less important features for those considered more important.

Given the significance accorded to the development of these design processes beginning with the kindergarten level, more research needs to be devoted to younger learners. Although engineering-based programs for the earlier grades are increasing, such as the seminal program, Engineering is Elementary ([EiE] Cunningham and 
Hester 2007; www.eie.org/), more research-based projects are needed. Compared to the proliferation of research outcomes for the upper secondary grades and college years, those for the younger grades appear limited. This could be due partly to the view that design processes are too complex for the younger grades, yet existing research has shown that young children have an emerging capacity to undertake simple design work such as imagining, planning, constructing, and evaluating (e.g., Bagiati and Evangelou 2015; Cunningham and Hester 2007; Dorie et al.'s 2014; Lachapelle and Cunningham 2014; Roth 1995; Watkins et al. 2014).

Given that the bulk of the research has targeted older learners, there is the need for an engineering design framework that also takes into account the younger grades. Drawing on Dorie et al.'s (2014) work in identifying design thinking in young children, as well as other research (e.g., Moore et al. 2014; Watkins et al. 2014), we developed a framework of engineering design processes for this study, as shown in Fig. 1.

The processes displayed in the framework reflect the multifaceted nature of a design approach. We consider the processes as inherently iterative (Dorst and Cross 2001; Lawson 2006; Watkins et al. 2014), such as idea generation frequently requiring revisiting problem scoping. As indicated in Fig. 1, we consider the application of STEM content knowledge during the design processes to be a key component of students' learning in solving engineering-based problems.

The framework served as a reference point in developing our activities and facilitated our identification and analysis of the students' developments, especially with respect to their group and class discussions. As Dorie et al. (2014) stressed, the simplified versions of engineering design that appear in programs such as Engineering is Elementary
(Cunningham and Hester 2007) tend to give limited attention to all the required design processes. With the NGSS (National Academies Press, 2013), however, processes such as problem scoping are being recognized as important from the early grades onwards.

\section{Processes of engineering design \\ Problem scoping}

Despite studies highlighting the importance of problem scoping, it nevertheless remains in need of further attention, especially for younger learners (Dorie et al. 2014). Even studies of undergraduate engineering classes have indicated that inadequate attention is given to problem scoping despite its importance in solving engineering problems in the workplace (Jonassen et al. 2006). Studies that have targeted the problem scoping of older students and adults (e.g., Atman et al. 2003; Cross and Cross 1998) have frequently focused on the time devoted to scoping a problem (e.g., Atman and Bursic 1998; Atman et al. 2007). For example, Atman et al. (2007) found that increased time devoted to problem scoping can yield enhanced engineering design solutions.

Although the literature remains limited with respect to younger students, embryonic research such as that of, Dorie and her colleagues (2014) and Watkins et al. (2014) are revealing how elementary students do engage in problem scoping as they solve early engineering-based problems. Building on Dorie et al.'s research, we view problem scoping as an important, underrepresented process of engineering design in the younger grades. Specifically, we consider problem scoping to entail clarifying and restating the goal of the problem, identifying constraints to be met in problem solution, exploring feasibility issues, drawing on related context to add meaning, experimenting with materials, and establishing collaborative group work.

\begin{tabular}{|c|c|c|c|c|}
\hline Problem Scoping & Idea Generation & $\begin{array}{l}\text { Design and } \\
\text { Construct }\end{array}$ & $\begin{array}{l}\text { Design } \\
\text { Evaluation }\end{array}$ & Redesign \\
\hline $\begin{array}{l}\text { Understanding } \\
\text { the boundaries of } \\
\text { a problem }\end{array}$ & $\begin{array}{l}\text { Brainstorming } \\
\text { and Planning }\end{array}$ & $\begin{array}{l}\text { Model } \\
\text { Development }\end{array}$ & $\begin{array}{l}\text { Meeting } \\
\text { Constraints }\end{array}$ & $\begin{array}{l}\text { Model } \\
\text { Redevelopment }\end{array}$ \\
\hline $\begin{array}{l}\text { - Clarify and } \\
\text { restate the } \\
\text { goal } \\
\text { - Identify } \\
\text { constraints } \\
\text { - Consider } \\
\text { problem } \\
\text { feasibility } \\
\text { - Add context } \\
\text { - Experiment } \\
\text { with materials } \\
\text { - Establish } \\
\text { collaboration }\end{array}$ & $\begin{array}{l}\text { - Share and } \\
\text { formulate } \\
\text { ideas } \\
\text { - Discuss } \\
\text { strategies } \\
\text { - Develop a } \\
\text { plan }\end{array}$ & $\begin{array}{l}\text { - Sketch design } \\
\text { - Interpret } \\
\text { design } \\
\text { - Transform } \\
\text { design to } \\
\text { model }\end{array}$ & $\begin{array}{l}\text { - } \text { Test model } \\
\text { - Check } \\
\text { constraints } \\
\text { - Assess goal } \\
\text { attainment }\end{array}$ & $\begin{array}{l}\text { - Review first } \\
\text { design } \\
\text { - Sketch new } \\
\text { design } \\
\text { - Transform } \\
\text { design to } \\
\text { revised model }\end{array}$ \\
\hline$\uparrow$ & $\uparrow$ & 4 & 4 & $\uparrow$ \\
\hline
\end{tabular}

Fig. 1 Processes of engineering design 
Designing effective solutions in the real world requires defining the goals to be achieved and identifying the often vague criteria and constraints to be met, while at the same time considering the boundaries of a problem that can be dynamic and open to debate. Problem scoping thus involves taking into account relationships among the problem components not just treating them in isolation. Furthermore, some might be more important than others and hence, prioritizing criteria might also be required (e.g., Cross and Cross 1998; Watkins et al. 2014).

Two features of problem scoping that were especially prevalent in Dorie et al.'s (2014) study were young children's spontaneous addition of a meaningful context to a problem and familiarizing themselves with materials supplied. For example, children added context by relating a tower they were constructing to a multi-level apartment building. Indeed, they were more inclined to add such context than their parents. Dorie et al.'s study also revealed how these children would not only explore the materials but also evaluate the items individually and discuss their properties and behaviors. Finally, we argue that problem scoping is strengthened when STEM content knowledge is applied, together with productive group collaborations, as students work towards problem solution (Diaz and King 2007; Moore et al. 2014).

\section{Idea generation}

As indicated in Fig. 1, we consider idea generation to encompass brainstorming and planning where students share and formulate ideas, discuss strategies, and develop a collaborative plan. These processes require strong team skills as students progress towards their initial model development. Such collaborative problem solving is being accorded greater international significance, as evident in the PISA (2015) Draft Collaboration Problem Solving Framework for assessing this skill. Productive communication among team members is cited as an essential element of the PISA Framework, where explaining ideas, justifying and defending arguments, and developing an in-depth understanding of solution processes are key features. These processes need to continue throughout the problem solution as students engage in design, model construction, testing, and redesign. The first author's prior research (English, Hudson, \& Dawes, 2013) revealed how constructive collaboration of this nature was essential to middle school students' achievements in engineering-based problem experiences.

\section{Design, construction, evaluation, and redesign}

The remaining processes of our framework (Fig. 1) entail sketching designs for initial model development, testing the model to ascertain whether constraints have been met, and modifying the initial design/s to produce an optimum model. The integral roles of design sketching are well documented in the literature (e.g., Anning 1997; Song and Agogino 2004; Tversky and Suwa 2009). For example, Song and Agogino's (2004) research with undergraduate engineering students indicated that the volume of total sketches and the number of 3-D sketches had an increasingly positive effect on design outcomes. Given that the activities we implement in the elementary school require students to draw their designs, this process is a key component of our framework.

Research on young students' design sketching in engineering activities is in its infancy (e.g., Portsmore 2010; Portsmore et al. 2012). Although research studies addressing children's engagement with design technology (e.g., MacDonald and Gustafson 2004) provide some insights into their abilities, the findings have been mixed. For example, some studies have questioned whether children should even be engaged in design drawing as they would rather experiment with materials instead (e.g., Welch and Lim 2000). Other research (e.g., MacDonald and Gustafson 2004) has even suggested that it is unnatural for young students to develop designs until their drawing skills are more developed. In contrast, there is research demonstrating how young learners can create designs that resemble their final products (e.g., Fleer 2000) and can engage in planning processes in which design sketching is a key component (e.g., Portsmore et al. 2012). These inconclusive findings highlight the need for further research on young students' design sketching as a key component of engineering-based problem solving.

We regard the comprehensive roles of design sketching, as identified by Song and Agogino (2004), to be pertinent to our work with young students. Specifically, a design sketch includes all forms of displayed representations, where the main features of an object or situation are conveyed in efforts to "give external definition to an imagined, or only half-imagined, suggestion for a design form" (p. 1). Such representations enable new ideas to be readily "tried out" on paper and can be subsequently re-examined and revised at a later point. Furthermore, students' design sketches serve to store possible solutions and can reveal whether constraints and criteria are likely to be met. Through their initial sketches, students can generate new ideas, develop conceptual STEM understanding, and transform their sketches into a 3-D model. On model testing, initial design sketches can be modified and transformed into improved models.

An important feature of the present problem was students' evaluation, documentation, and sharing of their initial designs including their transformation into 3-D models. These processes provide opportunities for students to reveal the extent to which they identify, understand, and link core concepts and principles within and across the STEM disciplines (Lachapelle and Cunningham 
2014; Lewis 2005). Furthermore, students were afforded opportunities to test their design and reflect on their launch technique as well as make changes that could optimize flight time. Such a problem was structured to engage students in the process of design related to a context rather than simply involve students in the design process through a procedural manner, where students may remain disconnected with the overall principles and concepts underpinning the problem solution (Bursic and Atman 1997; Daly et al. 2012; Watkins et al. 2014).

\section{Methods \\ Participants \\ Schools}

Five Queensland (Australia) schools, two private and three non-private (state), participated in the first year (fourth grade) of this 3-year longitudinal study. We chose to commence our work with fourth-grade classes given that our prior work with students in grades 7-9 (e.g., English, Hudson, \& Dawes, 2013) indicated that the processes of engineering design required long-term development and that this development needed to commence in the earlier grades. Both private and state schools were chosen as we were committed to introducing engineering education into both education sectors, where interest in STEM education is just emerging. Further, all schools indicated a keenness for their students to engage in these new learning experiences. Seven classes and their teachers completed the first year of activities, three from large private schools and the remainder from smaller state schools. We focus in this article on the three private school classes $(N=63$; mean age $=$ 9 years 8 months), given that their school timetabling and the students' greater fluency with the English language enabled more comprehensive data to be obtained.

\section{Teachers}

The learning experiences, which built on the teachers' existing mathematics, science, and technology curricula, were new to the teachers and their students. The teachers' involvement in the experiences across the study included regular briefing and debriefing meetings, before and after each problem implementation. We studied the teachers' mathematics, science, and technology programs, discussed the planning and implementation of activities that targeted core curricula goals and themes, reviewed the students' progress, and prepared subsequent activities taking into account the teachers' feedback and students' developments in the previous experiences. It was explained to the teachers that their direct intervention in the students' group work was not desirable. Learning was only facilitated where necessary, such as responding to a student's query by posing a thought-provoking question in return.

\section{Engineers}

We also involved practicing engineers from different fields for as many of the activities as they could attend, given their work commitments. The engineers were employees of our state Department of Transport and Main Roads, who supported our research project. Some engineers attended more than one school, such as a female civil engineer who was keen to visit a state and private school and shared her experiences in road design and construction. The engineers' sharing of their occupational experiences was especially valuable in enriching the real-world context of the activities. Where possible, the engineers also observed the students undertake the activities and we asked them to not directly influence their responses.

\section{Learning experiences and implementation}

The aims of our study included introducing students to the diverse world of engineering including exploring its different fields and ways in which engineers work towards improving society. Students' appreciation and application of the processes of engineering design underpinned each of the problem activities implemented during the study. It was important that students be encouraged to apply their own ideas and approaches to designing and creating their models, rather than a "conventional" approach that assumes students acquire and apply information in the exact form we desire and convey to them (Zawojewski et al. 2008).

The problem addressed here, the Aerospace Engineering Challenge, was the second of three multi-component activities that we had developed with the teachers during the first year of our study. The students had not been exposed to the fundamental principles of flight prior to the problem and had only been introduced to engineering design in the previous problem.

We chose the aerospace problem because it engages students in the processes of engineering design in an appealing and hands-on manner, and it draws upon core mathematics and science content of the teachers' curriculum (i.e., measurement, geometry, and forces). The problem also addressed components of their new technology curriculum including generating design ideas that match requirements and communicating the details of a design through a 3-D model ("physical prototype," Crismond and Adams 2012).

The problem spanned several class periods from early morning through to early afternoon, with one of the private schools completing the problem during the first period of the following day. The time devoted to the problem ranged from approximately $4 \mathrm{~h} 20 \mathrm{~min}$ to $5 \mathrm{~h}$ $30 \mathrm{~min}$. We supplied the teachers with detailed lesson booklets, including additional web-based resources on aerospace engineering, and provided workbooks for the 
students to complete individually. The students worked in small groups of three, occasionally four. The problem comprised three main components, as follows.

\section{Part 1. Exploring aerospace engineering and aerodynamics}

Before undertaking the problem, the class discussed aerospace engineering and the types of engineers who might work for an airline. Earlier in the school year, the students had explored a variety of engineering fields so they were readily able to offer suggestions. The term, "aerodynamics," was explained through a simple physical activity in which the students moved their hands through the air noting the effects of changing their palm direction.

Next, the students viewed a video clip of a Boeing 787 plane taking off and landing. While watching the video, the students were to think about (a) the movement and direction of the plane during take-off, flight, and landing, (b) the speed of the plane, and (c) the shape/features of the plane that enable it to fly. The students recorded their observations in their booklets and drew a simple outline of a plane labeling the nose, tail, wing, and body.

\section{Part 2. Designing, building, and testing a paper plane}

The problem commenced with a scenario about Qantas (a major Australian airline) seeking the students' assistance in developing educational material for its Longreach (Queensland) museum. The students' challenge was to design and build a paper plane that would stay in the air for as long as possible.

Prior to students' working the problem, a brief class discussion took place on the constraints that had to be met in designing and testing their plane to ensure these were understood. The students were also reminded of the engineering design processes they had used in the previous problem by revisiting the engineering story book, Engibear's Dream (King 2013), which proved a popular contextual reminder of the design process and the need to progressively record designs, observations, and redesigns. The basic "Engineering Design Model" (adapted from pbs.org) comprising Problem, Brainstorm, Design, Build, Test, Redesign, leading iteratively to Solution, was discussed prior to the working of the problem, with students labeling the model in their workbooks. Students were reminded, "When testing your planes, you can be thinking about ways to improve it because we will have a chance to redesign and retest".

Students were presented the following problem in their workbooks, together with safety information: (a) You will be working in groups of 3 or 4; (b) You will all get to make and fly your own plane; (c) Your plane is to be made from a single A4 sheet of paper; (d) Your plane is to be hand-launched; (e) Your plane is to be designed to stay in the air for as long as possible. Distance and speed are not as important as length of flight; (f) You will time your flight using a stop watch; and (g) You will have the chance to redesign your plane and try again to see if you can increase the time it stays in the air. The students were to record their responses in their workbooks including sketching and labeling the measurements of their design, their plane's time in the air, a description of how it had been launched, and their observations about its flight path and the way it landed.

\section{Part 3. Redesigning, reconstructing, and testing their planes}

This next part commenced with the students completing a few simple activities that illustrated the four forces associated with flight, namely, lift, thrust, drag, and weight. For example, to illustrate that lift is a pushing force created by the air, the activity, How Things Fly, from the Smithsonian National Air and Space Museum (http:// www.nasm.edu/galleries/gal109) was implemented. In their booklets, the students labeled the four forces acting on an illustrated plane and indicated the direction of each.

Next, the students discussed in their groups how and why they would change both their launch method and their initial design. Their deliberations were recorded in their individual workbooks. Applying their learning about forces, the students subsequently redesigned a new, group plane and recorded in their workbooks how and why they changed their design. On building their plane, testing it, and recording the time it stayed in the air, the students noted in their workbooks their observations regarding: (a) how they launched their plane, (b) the nature of its path in flight, and (c) the way in which the plane landed. Although the students worked as a group in their second plane design and testing, they were to record their own, personal responses.

In the final component of the problem, students completed a "Fact Sheet for the QANTAS Museum for their Education Centre". Each student recorded their responses to (a) the time the new plane stayed in the air, (b) why it was their best design, and (c) a description of the forces acting on the plane.

\section{Data sources}

Multiple sources of data collection were undertaken for this qualitative study. These included audio and video recordings of the focus groups as they solved the problem, as well as all whole-class discussions. Student workbooks were scanned and photos taken of the students' constructions. The researchers also completed written reflections on the problem's implementation.

Data for addressing each of the research questions were drawn from the student workbook responses. The first and fourth research questions were also answered through analysis of group transcripts as students worked the problem. 


\section{Data analysis}

The analysis adopted aspects of a grounded theory approach (Birks and Mills 2011), with constant comparative strategies (Strauss and Corbin 1990) used to identify patterns and trends in the students' responses. In using this method, we identified key themes in the students' designs as we indicate in the "Results" section. For example, it was evident that their designs could be characterized by the nature and extent of annotation such as the inclusion of measurements and calculations or detailed instructions on how to construct a plane.

Over several months, responses in the students' workbooks were repeatedly reviewed, coded, recoded, and subsequently refined. The coding of these responses was commenced by the first author, shared with the second author for checking, and where needed, revised with mutual agreement. Member checks were made with the research assistants and the teachers where necessary. As an example of our recoding, the number of sketches and templates students produced was included initially but was subsequently removed as it did not appear to have a bearing on the students' solutions, despite Song and Agogino's (2004) findings with adult designers. Our recoding also resulted in some minor adjustments to the design levels that we identified in the students' sketches after repeatedly checking these against levels.

We conducted iterative refinement cycles of analyses of the group and class transcripts for further evidence of students' learning (Lesh and Lehrer 2000). Through repeated analyses of the transcripts, we could identify examples of students engaging in the design processes indicated in Fig. 1 and how their movement through these processes appeared to facilitate a problem solution.

\section{Results}

In reporting our findings, we revisit our research questions in turn.

\section{Research question 1: What was the nature of students' initial designs and design processes?}

In addressing the nature of students' initial designs, consideration is first given to the annotated features identified in the analysis of the students' sketches, which also applied to the analysis of their redesigns. From this analysis, levels of sophistication with respect to the types and extent of annotations included were identified. In addressing the second component (i.e., design processes) of this question, examples are drawn from group transcripts during their initial designs.

\section{Coding scheme for annotations}

We use the term annotations in accord with Song and Agogino's (2004) definition, namely, a "type of support notation" metric, which includes "labels, lists, narratives, dimensions, and calculations" (p. 2). In identifying ways in which students annotated their sketches, we also looked for evidence of their application of disciplinary knowledge. Primarily, this was mathematics including linear measurement, geometry (perspective, shape construction and transformation, direction), and calculations. The final, non-hierarchical coding scheme of annotations displayed in both the design and redesign sketches is as follows.

\section{Basic sketch}

These design sketches displayed a basic drawing of a plane with body parts indicated (wings, tail, etc.) or a template of a plane.

\section{Measurements}

Such annotations were either basic or more detailed. For the former, at least one measurement was displayed on an illustration of a plane or template or listed on a workbook page. More detailed measurements were clearly marked on a plane illustration and/or template and/or listed on a page, in such a way that one could link the measurements to the plane's construction (e.g., through the use of directed lines indicating measurements; or a more detailed listing such as "nose to tail is $\mathrm{xx} \mathrm{cm").}$

\section{Perspective}

Perspective was featured on the design sketches, either through written words, such as "birds-eye view" or "sideview," and/or through more than one drawing of a plane or through multiple templates.

\section{Paper folding}

The annotations included some indication of how to fold the paper such as through simple labels, use of arrows, labeling of "1, 2, 3," or through a series of templates. However, no detailed written instructions were included. An example of a design sketch displaying this feature appears in Fig. 2.

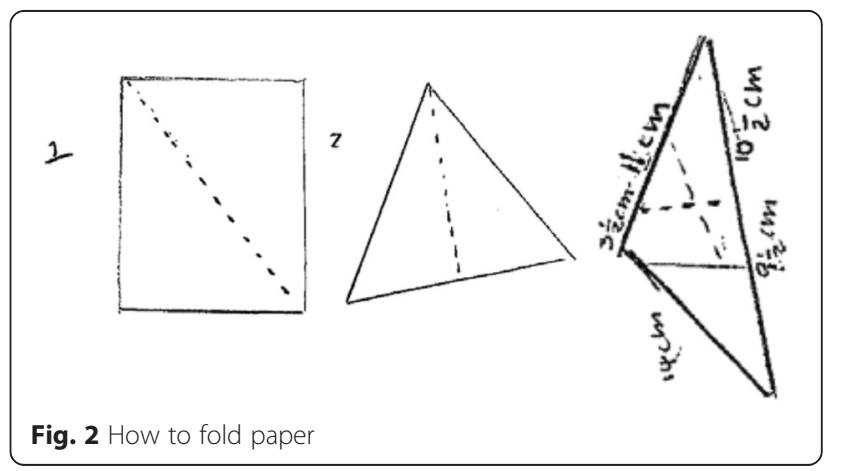




\section{Calculations}

The annotations included calculations such as that of a flight path, or total wing span, as illustrated in Fig. 3.

\section{Construction procedures}

Detailed instructions were provided on how to construct the plane, that is, a step-by-step procedure was included. Figure 4 presents an example of this design sketch.

\section{Design levels}

On coding the students' design sketches, we initially identified four levels of increasing sophistication with respect to the types and extent of annotations presented. However, given that there was only one student who displayed a fourth level in the first design sketch (and none in the redesign), we collapsed the fourth level into the third.

\section{Level 1}

This first level comprised designs that only exhibited a basic drawing of a plane with body parts indicated. Across the three classes $(N=62)$, approximately $21 \%$ of initial designs were at this level.

\section{Level 2}

Designs at the second level included an annotation that featured either basic measurements or more detailed measurements, or included an indication of how to fold the paper, or indicated perspectives. Through several iterations of analysis, we concluded that designs displaying these various features were not sufficiently different in sophistication and hence were assigned to the one level.
It is not surprising that Level 2 designs were most prevalent initially with approximately $60 \%$ of students' sketches classified at this level. Slightly less than half (49 \%) of the initial designs featured measurements that were not linked to the plane's construction (i.e., measurements that were written on the booklet page but not connected to the design). Approximately $10 \%$ included an indication of paper folding or more detailed measurements linked to the plane's construction.

\section{Level 3}

Designs assigned to the highest level displayed either multiple types of Level 2 annotations or included detailed written instructions on the plane's construction such as how to fold and where to fold the template. If a design sketch further included some calculations, it was incorporated in this third level, rather than being assigned to a fourth level. However, only $20 \%$ of initial designs were classified as Level 3.

In sum, the majority of students demonstrated the ability to design a plane through the use of annotated sketches that varied in the types and complexity of features displayed.

\section{Design processes}

We now review some of the design processes students displayed in their initial design creations, as evident in group transcripts. From the transcripts, it was apparent that students commenced with problem scoping where they frequently added familiar contexts (e.g., observing jet planes) to help them understand the boundaries of the problem and clarify its goal. Specifically, the issue

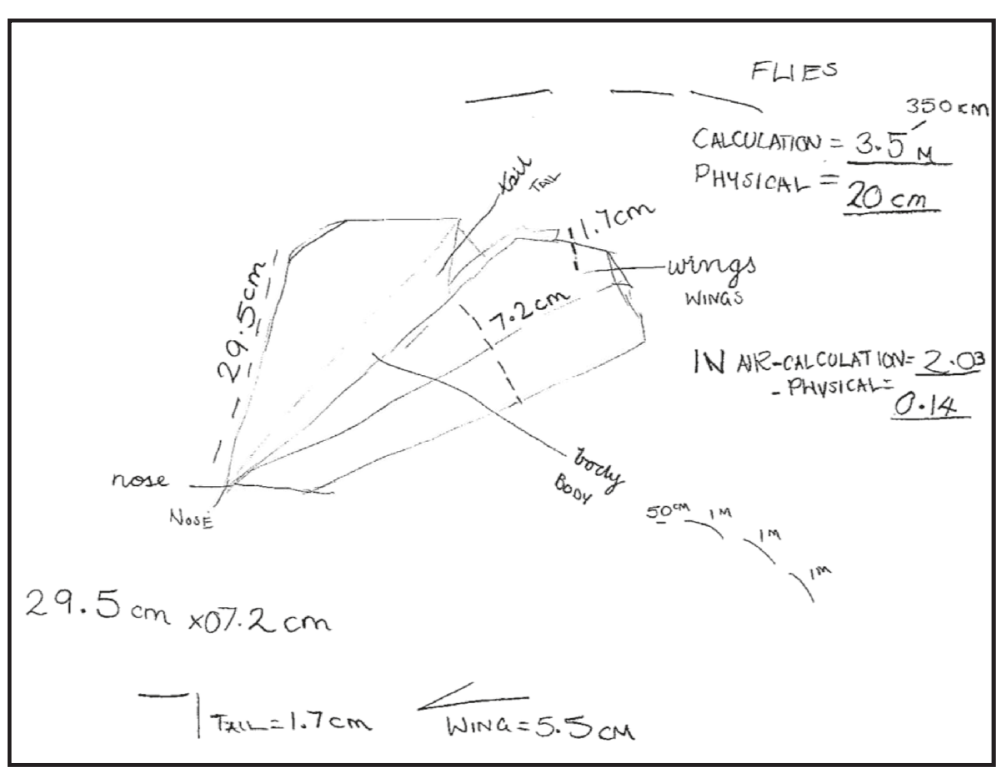

Fig. 3 Flight path calculations 


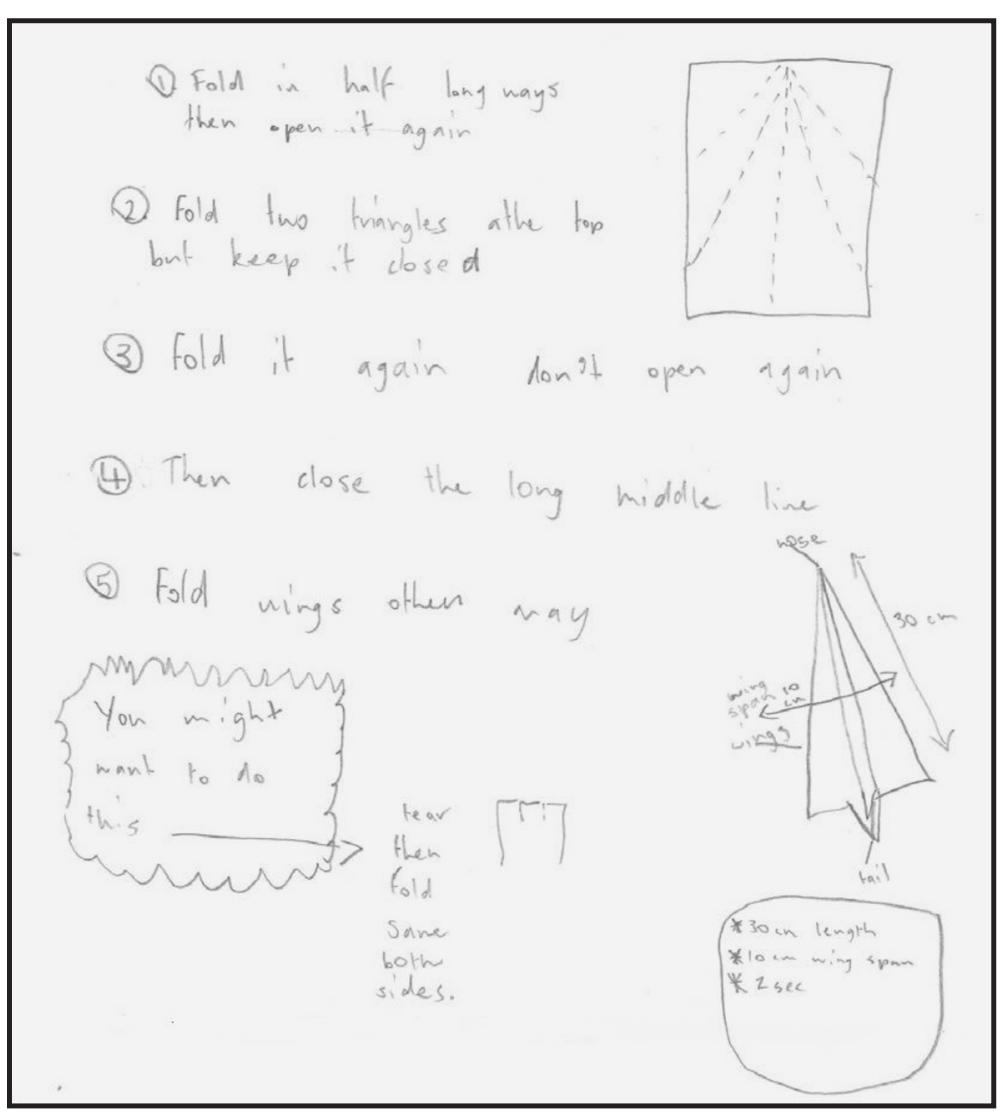

Fig. 4 Instructions on how to construct plane

arose of how closely the paper plane should be modeled on an actual aircraft. For example, Lilly's group suggested that "The way I'd design it is like a normal plane...because the wings should be flat...but if it's like a big wide plane, it has to be very thin so it can get through (the air) easily."

As her group continued to consider what was feasible given the problem constraints, they again referred to actual aircraft in debating whether to construct a large or small plane: "Big planes, they don't need much speed because the air, if it's coming up it can still push them." One group member retorted by illustrating with her hands that "If you push them too hard, when you go like that...it will kind of drop down straight away. It will start like that" (pushing her hand flat forwards from her shoulder height to desk height). The group experimented for a short while with the materials including the stop watch supplied for testing the planes but were brought back on task by a group member who noted, "Guys, we're not talking about stop watches at the moment. It's still design."

As illustrated in Lilly's group discussion above, a noticeable feature across the three classes was students' use of gesture as a means of "representational expressivity"
(Hegedus and Moreno-Armelia 2012, p. 49) as they attempted to convey their initial design ideas. A group member in another class, Mary's group, suggested, "Maybe we could make something with like, maybe like a tail at the end (placing her hands together to make a triangle shape, with fingers pointing up). So like there's something here, but then we have like the pointed end that gradually is getting bigger like that" (keeping her hands in a triangle shape, pointing her fingers to her right, and moving her hands across her body from right to left).

In an effort to understand this member's perspective in Mary's group, another questioned the feasibility of the design idea as she tried to visualize a tail that not only fitted with the member's perspective but could also be constructed. She queried, "But how are we going to get the paper to fold up? ... we're gonna have to cut a bit of paper off and stick it on".

Lilly's group also discussed strategies to transform their design ideas into a plane, with one member indicating how her inclusion of detailed instructions would facilitate construction: "I might draw the steps to make it so it's easier for me to do, and sometimes I can see if I do something wrong too. That's what I'm doing." Another member of the group was seemingly visualizing the transformation 
of their design into a 3-D model, commenting that "It may look a bit big when you do it and then in the end it's quite small".

Students continued to draw on the familiar context in their reflections on their plane constructions, with one of Lilly's group commenting, "My plane's not turning out exactly as it was supposed to," with another student replying, "Maybe this is how you make a jet plane. Do you think it looks like a jet? Or does it look too long?" Mary's group also expressed some dissatisfaction with transforming their design into a model, with one noting that "My design looks like a fish. Mine actually looks nothing like my design". Another concurred, stating, "My design was supposed to have a tail." Context was again added as these students attempted to account for their less-than-desired models: "Mine's a mega, mega, mega jet with dented wings ... has flown in a hailstorm".

In sum, the findings for the first research question indicate that students' engagement in the design processes included moving between problem scoping and idea generation in their conversations as they drew their initial design. In addition, their interactions revealed the importance of drawing on familiar context for developing ideas for the design.

\section{Research question 2: What were the students'} recommendations for improving their approaches to launching their planes?

This second research question explored students' learning following their initial design, the testing of their planes, and their introduction to the four forces of flight during a whole-class discussion. In their groups, the students proposed and justified changes they would make to their method of launching their plane to optimize goal attainment (i.e., maximum flight time).

In analyzing the workbook responses, consideration was given to evidence of students' application of mathematics and science knowledge. The former included measurement and geometry, specifically ideas pertaining to time, speed, angle, direction, properties of shapes, and shape transformation. The science component included application of the forces of flight to which the students had just been introduced.

\section{Coding scheme for improved launching recommendations}

In their booklets, students were asked to justify the changes to their launching technique because the launch contributes to the plane's successful flight. In coding the students' responses, we also included their justifications for why they would take their identified course of action to improve their launching techniques. Five nonhierarchical types of response were identified, as follows.

\section{No response or limited}

Students either did not respond or just stated that their method of launching would not change. Other responses in this category were of the type, "I'd change my throwing" or "Handle more carefully" or "Fly in a different way". Students" justifications included "nothing" or indicated satisfaction with the initial launch.

\section{Change in direction}

Responses in this category referred to a change in direction with respect to that of the wind or the nature of the launch, with the latter including throwing the plane upwards, in a straight line, or diagonally. An indication of how students would direct their body or body parts was also included here. Students' justifications included "Launching it higher so it will go upwards" or explaining that a direction such as "up" could cause the plane to "drop down".

\section{Targeting a plane component}

These responses focused on a particular plane component in the launch such as, "Throw the front first as fly further" and "Pointing the nose where I wanted it to fly." Students' main justification for this approach was to increase the length of time the plane stayed in the air.

\section{Adjusting the speed}

Students recommended adjusting the speed of the plane to improve the launch, with their justifications referring to increasing or decreasing the plane's speed.

\section{Adjusting forces}

Students referred to adjusting the nature of the force/s on launching the plane, for example, to give it more "thrust," more "force," or launching the plane "hard," "soft", or "gently".

Almost $20 \%$ of the students $(N=63)$ could not offer a suggestion for improving their launching technique. Nevertheless, $38 \%$ suggested a change in direction including how their body should be positioned in the launching process, and a further $11 \%$ recommended changing both direction and speed in maximizing time in the air. While these foregoing students did not refer specifically to any forces of flight, a core component in launching their planes, just over half of all students did consider this factor. Specifically, $30 \%$ commented on the impact of forces, with a further $29 \%$ including reference to forces as well as speed and/or direction as a means of launching their plane to maximize air time.

It appeared that students had some difficulty in justifying their recommendations for an enhanced plane launch (38\% of non-responses; $N=63$ ). The most common justification $(27 \%)$ pertained to maximizing air time, reflecting awareness of the goal. Approximately 
$20 \%$ of students referred to changing direction only or changing direction combined with maximizing air time or speed. Nevertheless, there was some awareness of the role of forces in the students' justifications, with $13 \%$ referring to this factor.

In sum, about one-third of students demonstrated science and mathematics ideas in the justification for an improved launch for increased air time. Interestingly, the application of disciplinary knowledge began to appear as students moved between the last two phases of the engineering design process (i.e., design evaluation and redesign).

\section{Research question 3: How did students propose to improve their designs to optimize goal attainment?}

Of interest in this third question were students' recommendations for improving their designs to increase the plane's air time and their reasons for these proposed changes. Their responses indicated an awareness of the need to better meet constraints and improve goal attainment by adjusting features of their plane, taking into account core mathematics and science ideas in doing so. Their application of discipline knowledge included geometric ideas focusing on shape, properties of shapes, shape transformation, and symmetry and aspects of measurement including length, thickness, and angle. Core science ideas were also applied in the students' explanations for their proposed design changes including improving air flow and capitalizing on the forces of flight.

Most students were able to suggest ways to improve on their initial designs. Their proposed improvements featured a range of changes including altering the shape of the plane (making it into a "triangle shape"), adding creases, folds, or holes, and adjusting "the small flaps at the back". References to "making it [plane] even more on an angle" and efforts to "make the top diagonal and fold it once more" were also recorded.

Other responses made specific reference to changing or adding the wings or nose, as well as adjusting the shape or length of these components. Such recommendations included changing the "wings into a kite shape", making the plane "thinner with longer wings", keeping the "wings flat instead of curved", "bending the nose", making the wings "bigger and nose straighter", and making the "wings even". The foregoing types of changes were fairly evenly distributed across the responses.

Similarly to their proposed launching justifications, students had difficulties in offering explanations for why they would alter their initial designs. Just over half of the students $(N=63)$ either offered no response or simply gave statements such as, "to make it fly better". A small percentage of students (14\%) identified body part/s that needed improving, changing, or adding with respect to shape, length, strength, thickness, or proportion of the body part in relation to the overall plane. Statements included converting the plane "into a triangle shape so I can have a proper nose," constructing "tougher wings," and correcting the tail ("the tail is pointing up like in the picture"). Although responses of this nature included some application of basic geometric and measurement ideas, how these changes would affect goal attainment was not evident.

More sophisticated explanations (32\%) included disciplinary knowledge that indicated some awareness of impact on goal achievement. That is, students referred to how their proposed design changes would impact on time in the air, speed of the plane, plane stability, improved gliding, or the effects of air flow or forces on maximizing air time. For example, reference to how changed airflow would increase air time included the trapping of more air, the addition of holes to let air through, and making adjustments for "cutting through the wind easier." Explanations that referred to forces of flight included the impact of the plane's weight on its time in the air ("weighing it down" so need to make plane "lighter") and giving the plane more "force" or "thrust".

The foregoing findings indicate that about one-third of students demonstrated the application of disciplinary knowledge in their recommendations for improving their designs; however, the reasons for their design changes were not well developed. In the next section, we note some changes in the students' explanations following their redesigns.

\section{Research question 4: What learning did students display across the problem?}

In addressing the last research question, we first document changes in students' design levels between their initial designs and their redesigns. Following this, we report on improvements in the students' explanations for their redesigns with a focus on their application of disciplinary knowledge. We then draw upon extracts from group transcripts to illustrate how students applied this knowledge in their efforts to improve on their initial designs.

\section{Changes in design levels}

Overall, we found a small improvement in students' second designs in the redesign phase.

With respect to the first design level, there was a slight increase in the number of designs that were coded as Level 1. That is, students' redesigns that featured just a basic drawing of a plane with body parts increased slightly from 21 to $26 \%$ [ $N=61$ ]. Level 2 responses (i.e., designs that included annotations) were also more prevalent in the students' redesigns, with a slight increase from the initial designs (from 60 to $64 \%$ ). 
Nevertheless, redesigns with annotations that comprised only non-linked measurements reduced from 49 to $43 \%$, while there was an increase in redesigns with an indication of how to fold the paper or the inclusion of more detailed, linked measurements (from 10 to $20 \%$ ). The most sophisticated design level, Level 3, was also not prevalent in the redesigns, with a decline in such responses (from 20 to $10 \%$ ). This decline, however, could have been attributed to one of the teachers allocating less time for the students' redesigns. Given that students' redesigns did not increase in sophistication greatly from initial to redesign, we suggest in the "Discussion" section some pedagogical strategies that may enhance students' designs. These findings, together with our own reflections, clearly indicate the need for increased attention on both the creation of initial designs and redesigns especially for our young learners.

\section{Application of disciplinary knowledge}

Students' explanations for their actual redesigns (i.e., second iteration of design) showed an improvement in their application of mathematics and science knowledge compared to their explanations for proposed design changes. At the same time, there was a decline in the number of students who were unable to offer an explanation for their actual redesigns ( $32 \%, N=63)$ compared to their previous proposed design changes. Of those students who could explain their redesigns, approximately $33 \%$ referred to the impact of their design changes on the plane's air time, its speed, and/or improved stability and gliding, while a further $17 \%$ indicated the effects of change on the air flow and forces acting on the plane. A further $16 \%$ of responses included a combination of these various factors. These findings suggest the importance of students experiencing the problem scoping and idea generation phases of our engineering framework for improved application of mathematics and science ideas in the subsequent phases.

To illustrate students' application of disciplinary knowledge in their efforts to improve on their initial designs, we consider excerpts from the group transcripts. We revisit firstly Lilly's group, who were reviewing how they might effectively combine the best features of their initial designs into a redesign. It can be seen in the following discussion how the students considered the interaction of mathematics and science components in undertaking a redesign while cognizant of the problem constraints. In contrast to their initial design discussions, which not surprisingly tended to focus on what was feasible within the problem constraints, the group's deliberations concentrated more strongly on applying disciplinary knowledge in modifying their initial designs.

The group commenced by reviewing the dimensions and positioning of their plane's wings, the overall shape of the plane, how they might address air flow, and how the forces of flight need to be taken into account. Taking into consideration the interactions among these factors, Lilly first suggested they "could use small (make the plane small) with big wings" with another member responding, "Okay, but one thing we're using from (another group member's first design) is pointing it upwards." Turning to another member's first design, Lilly queried, "What was good about your plane again?" Adele's response initiated the group's redesign:

Um, I don't know, but um, like maybe if you like only a little bit have the point of your plane curved in, a little bit, so it can like move ... See maybe at the back of the plane we should have little triangle cuts or something.

Although neither scissors nor tape was supplied, the group discussed the effects of cutting "little triangles" but then considered this to be problematic because "... then the wind will catch on it. Maybe not." The group then returned to the problem constraints, questioning what might be permitted and what would be feasible:

Amy: Yeah, but we can't do small (make a small plane) using an A4 piece of paper.

Adele: No, we can fold it or rip it.

Lilly: No we can halve it.

Adele: No we have to use one, an A4.

Lilly: Can't we halve the paper?

On being informed they could halve their sheet, the group proceeded to document their decisions to date, indicating how they were aware of the potential interactions among their plane features. The need to balance the size and shape of the body parts to maximize thrust during flight, with the aim of increasing the distance traveled, was also evident in their development of a redesign:

Lilly: Flexible nose. Bent wings. Big wings, so it can lift more.

Adele: Wings with up-turns.

Lilly: Yeah ... maybe not the triangle things. Because like, I'm just saying like ... it can, the wind can catch onto it more and make it slow down ... Yeah we can do the triangles at the back. But not so the wind can get off it more (making wave motions with hands).

On being questioned by the first author on their proposed redesign, the group explained how they aimed to control for the wind factor (thereby increasing thrust) by incorporating "flaps" and "cut-outs" in their design; again they appeared cognizant of the broader problem goal of maximizing the plane's flight path:

Adele: We're gonna do kind of like this. So we're gonna have like that (indicates flaps on wings), and then we're gonna have mini like cut-outs at the back.

Author: Why have you decided on that?

Adele: Um, so that we can kind of like catch ... onto like the plane and push it along ... and also it's, that 
(indicates flaps and cut-outs) will control the wind, and if it's small it can go further a little bit and it will go longer sometimes.

Lilly: Yeah and if it has bigger wings it can lift it up.

Adele: And a flexible nose ... that can turn itself so it can like stay there so it can have longer time in the air.

The above excerpt indicates how the students' effective collaboration fuelled productive idea generation for optimizing the goal in a redesign. Their discussions suggest an understanding of the need to control the force of the wind to keep the plane in the air. Modifications to the plane's features (e.g., "mini like cut-outs at the back") that might "catch" the wind and "push it along" were entertained.

On transforming these ideas into a revised plane model, Lilly's group decided to make their wings wider but added "mini wings" (two small flaps, each about $1.5 \mathrm{~cm}$ long, torn into the back of the plane) so "we had more lift ... and it (the air) can push it more because there's more space". In justifying the inclusion of the flaps, Lilly brought in the familiar context used in their initial designs, namely, "It's just because we saw them on the other planes, like on real planes, so we thought that might help". On reporting to the class, however, Lilly's group explained that they thought the flaps might assist the plane to "run through, gently through the air but it kind of dragged it". The group also created a "flexible nose that we thought would be good for steering" and "so it could turn around if the wind pushed it". The group appeared aware of the forces involved in flight and how the shape and size of their plane's body parts, together with added features, might govern the impact of these forces.

Other groups also demonstrated an increased focus on applying their disciplinary knowledge in weighing up the strengths and weaknesses of their initial design. Mary's group, for example, was concerned about the tail of their first plane, commenting that it "sort of sticks up the top" and is "a bit far forward." The group reflected on how they made the tail in their initial design shorter "so it would maybe take the resistance more and keep it up". The group decided to retain the size of the tail because "we think the lighter the plane the less weight it will take up..." and "so the wind in the air will hold it up for longer". Mary subsequently expressed concerns about the width of their plane, explaining that "it's very wide". Another group member disagreed, arguing that "it will kind of cut through the air because of that shape".

Stacey's group decided that longer wings would enhance goal attainment by improving the plane's ability to glide and thus remain airborne for longer: "We changed the shape (of the plane) because we made the wings longer and put in some crinkles. This was to help the plane fly for longer." When asked why, the group responded,
"Because the wing span's practically bigger and it will stabilize it." The application of disciplinary knowledge in the redesign phase is evident in the foregoing studentstudent interactions. In sum, the students displayed some improvement in the sophistication of their designs and a stronger application of mathematics and science ideas in the redesign phase.

\section{Discussion}

Our study has provided an example of how fourth-grade students can engage in processes of engineering design and apply disciplinary knowledge in solving a meaningful and appealing problem. In accord with calls for better integration of the STEM disciplines and a more balanced representation of content (e.g., Honey et al., 2014), we developed the Aerospace Challenge drawing on the teachers' science, mathematics, and technology programs. Building largely on Dorie et al.'s (2014) research, we developed an engineering design framework for this study that would cater for multiple processes in early engineering education. The five main interactive processes of problem scoping, idea generation, design and construction, design evaluation, and redesign formed our framework, with each comprising a number of components playing key roles in problem solution. The development and application of STEM content knowledge is an important feature of the framework, reflecting the well-documented role of such learning during design (e.g., Crismond and Adams 2012; Diaz and King 2007; Moore et al. 2014). Likewise, the establishment of productive collaborative groups at the outset of problem solution is an important feature.

In addressing our first research question, we analyzed the students' sketches of their initial designs focusing on their use of disciplinary knowledge (i.e., measurement, geometry, and forces) and their forms of annotation, in accord with Song and Agogino's (2004) support notation metric. Three levels of increasing sophistication in the students' sketches were identified, with the second level the most prevalent. Students at this level were able to develop designs that encompassed drawings or templates with an indication of how to fold the paper as well as measurements linked to the plane's construction. The most sophisticated level incorporated multiple forms of annotations or included written instructions and calculations. This third level was not prominent, however, which is not surprising given that the current problem was only the students' second engineering-based problem experience.

The first research question also explored students' initial design processes during group work, where examples of the different processes of our framework appeared. Problem scoping was prominent, with the addition of familiar contexts featured as well as an awareness of constraints 
and a consideration of what was feasible in designing their plane. The important role of context in engineering design for young learners, as shown in Dorie et al.'s (2014) work, complements research showing how context has a bearing on students' approaches to problem solving in other domains such as statistics (English 2013a). More research is needed on ways in which context can facilitate (or even hinder) young children's clarification of the problem goal, assist in generating design ideas, and serve as a reference point in transforming these ideas into a 3-D model.

The use of gesture as a form of "representational expressivity" (Hegedus and Moreno-Armelia 2012, p. 49) in conveying ideas on possible designs was an unexpected observation. The important role of hand gestures, which resemble physical similarities to the objects being designed and embody the knowledge one is trying to convey, has been well noted in the literature (e.g., Crismond and Adams 2012; Heiser et al. 2009). We suggest that more recognition be given to the use of gestures in conveying design ideas, especially for young learners who naturally use physical actions in communicating with others. In sum, the findings from the first research question reveal how our students could complete initial designs of planes at varying levels of complexity.

In reviewing the second research question, it appears that the introduction to the forces of flight facilitated students' discussions on how to improve their launching techniques. At the same time, students were able to apply their mathematics knowledge in conjunction with their new science learning in their deliberations. The difficulties some students experienced in justifying improvements to their launching indicate the need for further attention, although recording their justifications in written form might have been an inhibiting factor.

The third research question considered students' proposals for improving their initial designs to increase their plane's air time. Students again demonstrated disciplinary knowledge as they recommended adjusting features of their plane. They combined ideas from mathematics such as making adjustments to the length, shape, thickness, or proportion of body parts, with ideas from science where they addressed improving air flow and capitalizing on the forces of flight in their redesigns. The emergence of explanations that indicated some understanding of how their changes would impact on goal attainment was promising, such as removing a section/s or making the plane lighter to streamline the plane's flight and thus lengthen its duration. Furthermore, these findings indicate the importance of the redesign phase in students' development of disciplinary knowledge.

The final research question, namely students' overall learning, did not indicate major changes with respect to design levels although students included more detailed annotations such as how to fold the paper in constructing their plane and how their measurements linked to specific body parts in the second design. The third level, however, was rarely displayed. It would seem that for young learners, more attention could be devoted to the redesign component including a focus on evaluating products from initial designs and identifying their strengths and limitations. One pedagogical approach may be for teachers to spend more time in whole-class discussions unpacking the outcomes of the first test flight and encouraging ideas for improvements to the design for maximizing flight time.

Despite the limited change in the design levels, students showed considerable improvement in how they applied their mathematics and science learning to the redesign process. Well over half of the students could explain how their design changes targeted the problem goal, including reference to the impact of the forces of flight. Excerpts from the group transcripts illustrated how students applied their learning in reviewing their initial designs.

We conclude from this study that well-structured engineering experiences provide opportunities for students to engage in the design processes connected to an aerospace context. Although only slight improvements occurred in the sketches between the design and redesign phases, the study reveals that students could sketch planes of varying levels of sophistication that translated into models. We suggest that scaffolding by the teacher about how to improve designs for increased detail could be included in subsequent experiences (cf. Anning 1997). In the last two phases of our engineering framework (evaluation, redesign), students began to apply disciplinary knowledge when recommending an improved launch technique and when explaining changes for their second design. The study highlights the importance of affording students the opportunity to complete their initial designs, then build and test their models, and subsequently negotiate and create a second design. This opportunity appeared to have contributed to students' improved application of disciplinary knowledge in the final phases of our engineering framework.

\section{Limitations}

Before noting additional contributions of our study, we need to acknowledge some of its limitations. First, our study was confined to classrooms in just five schools with the present findings derived from one problem implemented within non-state school classes. In addition, we were faced with the realities of research settings that are highly variable in their day-to-day happenings. Although we had prepared detailed teachers' booklets including recommended timing, there were some natural variations in the time teachers devoted to each part of 
the problem. For example, the timetable of one school enabled the students to complete their redesigns the next morning; this was not feasible in the other school with possible effects on the limited improvements in redesign levels.

Second, variations in the young students' abilities to communicate and document their ideas orally and/or in written forms including their design sketches could be considered another limitation. In our analysis of the students' oral and written work, we tried to address this limitation by simultaneously referring to all the video and audio transcriptions. Furthermore, in analyzing the students' design sketches, we were not concerned with the quality of their illustrations per se, rather, the forms of annotation that they included. We also checked the students' sketches alongside their workbook descriptions of their designs.

Third, the nature of our qualitative data meant that our coding of the students' responses could have varied somewhat had more researchers been engaged in the process. Nevertheless, our triangulation of data sources enabled us to repeatedly review and refine our interpretations of the students' responses and jointly modify our coding where needed.

\section{Conclusions}

Within the limitations acknowledged, we suggest that our study offers a number of contributions to early engineering education research in addition to those we have noted in our "Discussion" section. Our study has supported existing research indicating the potential of young learners in solving engineering-based problems, including their engagement in design processes and their application of disciplinary learning. The students' abilities to link mathematics and science ideas during a problem solution provide one example of how we might address STEM integration and aim for a more balanced discipline representation. We argue, however, that teacher scaffolding in introducing students to new content, such as the principles of flight, is an important factor here. Appropriate scaffolding from adults, as demonstrated in Dorie et al.'s (2014) study, can promote the "natural" engineering talents of young learners. We recommend that such scaffolding needs to be balanced in terms of establishing an understanding of core concepts and allowing students to apply this learning in ways they choose during the design processes.

There are many areas in need of further research that can be investigated through introducing younger students to engineering education, a field that appears to be in its infancy especially on an international scale. Our students' apparent natural abilities to engage in engineering design processes suggest that such engagement could be encouraged in problem solving across all the
STEM disciplines. Such a broadened perspective on engineering design is slowly emerging, as evident in the NGSS, but could receive greater attention from both curriculum developers and researchers. As Bagiati and Evangelou (2015) have noted though, while there are scattered resources available for early engineering education, they often lack clear learning goals, tools for assessing students' learning, and sufficient teacher support. Given that design is increasingly responsible for the creation of most items that support our day-to-day lives (Miaoulis 2014), more research-based programs that facilitate early engineering learning appears warranted.

\section{Competing interests}

The authors declare that they have no competing interests.

\section{Authors' contributions}

The authors collected the data collaboratively. LDE took primary responsibility for data analysis and writing the article but was supported by DTK in multiple improvements of the article. DTK checked all data analysis, their interpretations, and the associated results and conclusions. Both authors read and approved the final manuscript.

Received: 1 November 2014 Accepted: 27 July 2015

Published online: 19 August 2015

\section{References}

Anning, A. (1997). Drawing out ideas: graphicacy and young children. International Journal of Technology and Design Education, 7, 219-239.

Atkinson, R. D, and Mayo, M. (2010). Refueling the U.S. innovation economy: Fresh approaches to science, technology, engineering and mathematics (STEM) education. Washington, DC: Information Technology and Innovation Foundation. Available on-line at http://www.itif.org/files/2010refuelinginnovation-economy.pdf.

Atman, CJ, Adams, RS, Mosborg, S, Cardella, M, Turns, J, \& Saleem, J. (2007). Engineering design processes: a comparison of students and expert practitioners. Journal of Engineering Education, 96(4), 359-379.

Atman, CJ, \& Bursic, KM. (1998). Verbal protocol analysis as a method to document engineering student design processes. Journal of Engineering Education, 87(2), 121-132.

Atman, C. J., Turns, J., Cardella, M., \& Adams, R. S. (2003). The design processes of engineering educators: thick descriptions and potential implications. In Expertise in Design: Design Thinking Research Symposium (Vol. 6). Retrieved from http://research.it.uts.edu.au/creative/design/papers/32AtmanDTRS6.pdf.

Bagiati, A., and Evangelou, D. (2015). Engineering curriculum in the preschool classroom: the teacher's experience. European Early Childhood Education Research Journal (online 19 Jan.)

Barrett, B. S., Moran, A. L., \& Woods, J. E. (2014). Meteorology meets engineering: an interdisciplinary STEM module for middle and early secondary school students. International Journal of STEM Education, 1:6 doi:10.1186/2196-7822-1-6.

Berland, LK. (2014). Designing for STEM integration. Journal of Pre-College Engineering Education Research (J-PEER), 3(1), Article 3. http://dx.doi.org/ 10.7771/2157-9288.1078.

Birks, M, \& Mills, J. (2011). Grounded theory: a practical guide. Los Angeles: Sage.

Bursic, KM, \& Atman, CJ. (1997). Information gathering: a critical step for quality in the design process. The Quality Management Journal, 4(4), 60-75.

Crismond, DP, \& Adams, RS. (2012). The informed design teaching and learning matrix. Journal of Engineering Education, 101(4), 738-797.

Cross, N, \& Cross, A. (1998). Expert designers. In E Frankenburger, P Badke-Schaub, \& H Birkhofer (Eds.), Designers - the key to successful product development. London: Springer Verlag.

Cunningham, CM, \& Hester, K. (2007). Engineering is elementary: an engineering and technology curriculum for children. Honolulu, HI: Proceedings of the American Society for Engineering Education Annual Conference and Exposition.

Cunningham, CM, \& Lachapelle, CP. (2014). Designing engineering experiences to engage all students. In S Purzer, J Strobel, \& M Cardella (Eds.), Engineering in 
pre-college settings: synthesizing research, policy, and practices (pp. 117-142). Lafayette, IN: Purdue University Press.

Daly, SR, Yilmaz, S, Christian, JL, Seifert, CM, \& Gonzalez, R. (2012). Design heuristics in engineering concept generation. Journal of Engineering Education, 101(4), 601-629.

Diaz, D, \& King, P. (2007). Adapting a post-secondary STEM instructional model to K-5 mathematics instruction. Honolulu, HI: Proceedings of the American Society for Engineering Education Annual Conference and Exposition.

Diefes-Dux, H. A., Hjalmarson, M., Miller, T., and Lesh, R. (2008). Model eliciting activities for engineering education. In J. Zawojewski, H.A. Diefes-Dux and K. Bowman (Eds.) Models and Modeling in Engineering Education: Designing Experiences for All Students (pp. 17-35). Rotterdam: Sense Publishers.

Dorie, BL, Cardella, ME, \& Svarovsky, GN. (2014). Capturing the design thinking of young children interacting with a parent. Indianapolis, IN: Paper presented at the 121st SEE Annual Conference and Exposition.

Dorst, K, \& Cross, N. (2001). Creativity in the design process: co-evolution of problem-solution. Design Studies, 22(5), 425-437.

English, L. D. (2015). STEM: Challenges and Opportunities for Mathematics Education. In K. Beswick, T. Muir, \& J. Wells (Eds.). Proceedings of the 39th Conference of the International Group for the Psychology of Mathematics Education (Vol. 1, pp. 4-18). Hobart, Australia: PME.

English, L. D., Hudson, P., \& Dawes, L. (2013). Engineering-based problem solving in the middle school: Design and construction with simple machines. Journal of PreCollege Engineering Education, 3(2), article 5. DOl:10.7771/2157-9288.1081.

English, L. D. (2013a). Reconceptualising statistical learning in the early years. In L. D. English \& J. Mulligan (Eds.), Reconceptualising early mathematics learning (pp. 67-82). Dordrecht: Springer.

Fleer, M. (2000). Working technologically: investigations into how young children design and make during technology education. International Journal of technology and Design Education, 10(1), 43-59.

Furner, J, \& Kumar, D. (2007a). The mathematics and science integration argument: a stand for teacher education. Eurasia Journal of Mathematics, Science \& Technology, 3(3), 185-189.

Hegedus, S, \& Moreno-Armelia, L. (2012). Intersecting representation and communication infrastructures. In S Hegedus \& J Roschelle (Eds.), The SimCalc vision and contributions: democratizing access to important mathematics (pp. 47-62). Netherlands: Springer.

Heiser, J, Tversky, B, Lee, P, \& Daniel, M. (2009). Explanations in gesture, diagram, and word. In KR Coventry, T Tenbrink, \& JA Bateman (Eds.), Spatial language and dialogue (pp. 119-131). Oxford: Oxford University Press.

Holmes, M., Rulfs, J., and Orr, J. (2007). Curriculum development and integration for K-6 engineering education. Paper presented at the 2007 ASEE Annual Conference and Exposition. Hawaii.

Honey, M., Pearson, G., and Schweingruber H (Eds.). (2014). STEM integration in K-12 education: Status, prospects, and an agenda for research. Washington: National Academies Press

Hudson, P. B., English, L. D., \& Dawes, L. (2014). Curricula integration: Identifying and locating engineering education across the Australian Curriculum. Curriculum Perspectives, 34(1), 43-50.

International Technology Education Association (ITEA). (2000). Standards for technological literacy: content for the study of technology (1st ed.). Reston, VA: ITEA.

Jonassen, D, Strobel, J, \& Lee, CB. (2006). Everyday problem solving in engineering: lessons for engineering educators. Journal of engineering education, 95(2), 139-151.

Katehi, L, Pearson, G, \& Feder, MA (Eds.). (2009). Engineering in K-12 education: Understanding the status and improving the prospects. Committee on K-12 Engineering Education. National Academy of Engineering, National Research Council. Washington, DC: National Academies Press.

King, A. (2013). Engibear's dream. Illus by B. Johnston. Frenchs Forest, Australia: Little Steps Publishing.

Lachapelle, CP, \& Cunningham, CM. (2014). Engineering in elementary schools. In S Purzer, J Strobel, \& M Cardella (Eds.), Engineering in pre-college settings: research in synthesizing research, policy, and practices (pp. 61-88). Lafayette, IN: Purdue University Press.

Lawson, B. (2006). How designers think: the design process demystified (4th ed.). Oxford: Architectural Press.

Lesh, R, \& Lehrer, R. (2000). Iterative refinement cycles for videotape analyses of conceptual change. In R Lesh \& A Kelly (Eds.), Research design in mathematics and science education (pp. 665-708). Hillsdale, NJ: Erlbaum.

Lewis, T. (2005). Coming to terms with engineering design as content. Journal of Technology Education, 16(2), 34-51.
MacDonald, D, \& Gustafson, B. (2004). The role of design drawing among children engaged in a parachute building activity. Journal of Technology Education, 16(1), 55-71.

Mehalik, MM, Doppelt, Y, \& Schun, CD. (2008). Middle-school science through design-based learning versus scripted inquiry: better overall science concept learning and equity gap reduction. Journal of Engineering Education, 97(1), 71-81.

Miaoulis, I. (2014). K-12 engineering: the missing core discipline. In S Purzer, J Strobel, \& M Cardella (Eds.), Engineering in Pre-college settings: research into practice (pp. 21-34). West Lafayette, Indiana: Purdue University Press.

Moore, TJ, Glancy, AW, Tank, KM, Kersten, JA, Smith, KA, Karl, A, \& Stohlmann, MS. (2014a). A framework for quality K-12 engineering education: research and development. Journal of Pre-College Engineering Education, 4(1), Article 2. http://dx.doi.org/10.7771/2157-9288.1069.

Moore, TJ, Stohlmann, MS, Wang, H, Tank, KM, Glancy, AW, \& Roehrig, GH. (2014b). Implementation and integration of engineering in K-12 STEM education. In S Purzer, J Strobel, \& M Cardella (Eds.), Engineering in Pre-college settings: research into practice (pp. 35-60). West Lafayette, Indiana: Purdue University Press.

National Academies Press (2013). Next generation science standards: for states, by states. Washington: National Academy of Sciences.

National Academy of Engineering and National Research Council (NAE and NRC). (2009a). Engineering in K-12 education: understanding the status and improving prospects. Washington, DC: National Academies Press.

National Research Council. (2009). Rising above the gathering storm two years later: accelerating progress towards a brighter economic future. Washington, DC: The National Academies Press. http://www.nap.educ/ catalog/12537.

National Research Council. (2012). A framework for K-12 science education: practices, crosscutting concepts, and core ideas. Washington, DC: The National Academies Press.

National Research Council. (2014). STEM learning is everywhere: summary of a convocation on building learning systems. Washington, DC: The National Academies Press.

PISA 2015: Draft collaborative problem-solving framework. March, 2013. (http://www.oecd.org/pisa/pisaproducts/Draft\%20PISA\%202015\%20 Collaborative\%20Problem\%20Solving\%20Framework\%20.pdf)

Portsmore, M. (2010). Exploring how experience with planning impacts on first grade students' planning and solutions to engineering to engineering design problems. Education. Medford, MA: Tufts University. PhD.

Portsmore, M, Watkins, J, \& McCormick, M. (2012). Planning, drawing and elementary students in an integrated engineering design and literacy activity (Paper presented at the 2nd P-12 engineering and design education research summit). DC: Washington.

Purzer, S, Hathaway Goldstein, M, Adams, R, Xie, C, \& Nourian, S. (2015). An exploratory study of informed engineering design behaviors associated with scientific explanations. International Journal of STEM Education, 2, 9. doi:doi:10.1186/s40594-015-0019-7.

Purzer, S, Strobel, J, \& Cardella, ME (Eds.). (2014). Engineering in pre-college settings: synthesizing research, policy, and practices. Purdue: Purdue University.

Roth, W-M. (1995). From "wiggly structures" to "unshaky towers": Problem framing, solution finding, and negotiation of courses of actions during a civil engineering unit for elementary students. Research in Science Education, 25(4), 365-381.

Shaughnessy, M. (2013). Statistical literacy and the 2013 International Year of Statistics. (President's message). National Council of Teachers of Mathematics. http:// atmopav.com/wp-content/uploads/2012/08/Presidents-Message-Sept-2012.pdf (accessed October, 2014).

Song, S, \& Agogino, AM. (2004). Insights on designers'sketching activities in new product design teams (Proceedings of the DETC'04 ASME 2004 Design Engineering Technical Conference and Computers and Information in Engineering Conference (pp. 1-10), September 28 - October 2, 2004). Utah: Salt Lake City.

Stinson, K, Sheats Harkness, S, Meyer, H, \& Stallworth, J. (2009). Mathematics and science integration: models and characterizations. School Science and Mathematics, 109(3), 153-161.

Stohlmann, M, Moore, TJ, \& Roehrig, GH. (2012). Considerations for teaching integrated STEM. Journal of Pre-College Engineering Education Research (J-PEER), 2(1), Article 4. http://dx.doi.org/10.5703/1288284314653.

Strauss, A., \& Corbin, J. (1990). Basics of qualitative research: Ground theory procedures and techniques. Thousand Oakes, CA: Sage Publications Inc. 
Task Force Report, STEM. (2014). Innovate: a blueprint for science, technology, engineering, and mathematics in California public education. Dublin, California: Californians Dedicated to Education Foundation. http://www.cde.ca.gov/nr/ ne/yr14/yr14rel71.asp

The National Academies (2014). Next Generation Science Standards: For States, By States. Washington: National Academy of Sciences.

Tversky, B. and Suwa, M. (2009). Thinking with sketches. In A. B. Markman and K. L. Wood (Eds), Tools for innovation. Oxford: Oxford University Press.

Walkington, C, Nathan, M, Wolfgram, M, Alibali, M, \& Srisurichan, R. (2014). Bridges and barriers to constructing conceptual cohesion across modalities and temporalities: challenges of STEM integration in the pre-college engineering classroom. In S Purzer, J Strobel, \& M Cardella (Eds.), Engineering in Pre-college settings: research into practice (pp. 183-210). West Lafayette, Indiana: Purdue University Press.

Watkins, J, Spencer, K, \& Hammer, D. (2014). Examining young students' problem scoping in engineering design. Journal of Pre-College Engineering Education Research, 4(1), Article 5. http://dx.doi.org/10.7771/ 2157-9288.1082.

Welch, M, \& Lim, HS. (2000). The strategic thinking of novice designers: discontinuity between theory and practice. The Journal of Technology Studies, 26, 2.

Wright, T. (2006). Science in the middle years: building a model for the integrated curriculum. Australian Journal of Middle Schooling, 6(2), 19-26.

Zawojewski, J. S., Diefes-Dux, H. A., and Bowman, K. J. (2008). (Eds.), Models and modeling in Engineering Education: Designing experiences for all students. Rotterdam: Sense Publications.

Zawojewski, JS, Hjalmarson, JS, Bowman, K, \& Lesh, R. (2008b). A modeling perspective on learning and teaching in engineering education. In J Zawojewski, H Diefes-Dux, \& K Bowman (Eds.), Models and modeling in engineering education: designing experiences for all students (pp. 1-16). Rotterdam: Sense Publications.

\section{Submit your manuscript to a SpringerOpen ${ }^{\circ}$ journal and benefit from:}

- Convenient online submission

- Rigorous peer review

- Immediate publication on acceptance

- Open access: articles freely available online

- High visibility within the field

- Retaining the copyright to your article

Submit your next manuscript at $>$ springeropen.com 